\title{
A DIDÁTICA NA LITERATURADE TÉCNICAS ESTENDIDAS DE PRODUÇÃO DE SOM PARA VIOLINO
}

\section{TEACHING IN THE LITERATURE OF EXTENDED SOUND PRODUCTION TECHNIQUES FOR VIOLIN}

Lourenço De Nardin Budó

Idb807@gmail.com 


\section{Resumo}

Este artigo é um passo no sentido da organização do corpus de recursos didáticos para a prática de técnicas estendidas para violino através de uma investigação exploratória bibliográfica. $\mathrm{O}$ trabalho parte de uma proposta de categorização de técnicas estendidas, o que permite estudá-las mais detalhadamente, e concentra-se na categoria que foi definida como "técnicas de produção de som específicas do violino". O estudo resulta na constatação de uma considerável quantidade de obras textuais e musicais. Dentre as obras textuais, apesar de todas terem alguma relevância, nem todas têm cunho decididamente didático; dentre as obras musicais, a amostragem trouxe uma quantidade pequena de estudos e peças realmente voltados especificamente para esta categoria de técnicas.

Palavras-chave: Violino; Técnicas estendidas; Técnicas expandidas; Ensino do instrumento; Literatura didática.

\section{Abstract}

The present article is a step towards organizing the corpus for extended violin techniques didactic resources, by the means of an exploratory bibliographic investigation. It departs from a proposed categorization of extended techniques, which enables studying them in more detail, and has been focused in the category defined as "sound production techniques specific to the violin". The study has found that there is a considerable amount of textual and musical works. Among textual works, despite all of them having some relevance, not all of them are decidedly didactic; among the musical ones, the sample has brought a small number of etudes and pieces that in fact explore this category of techniques.

Keywords: Violin. Extended techniques. Instrument teaching. Didactic literature. 


\section{INTRODUÇÃO}

Esta pesquisa ${ }^{2}$ foi impulsionada por um sentimento de dissociação entre ensino e prática de técnicas estendidas, ${ }^{3}$ posto que, apesar destas serem recorrentes na atualidade, a maior parte dos estudos e métodos de ensino está centrada no repertório violinístico dos séculos XVIII e XIX. Marcações como, por exemplo, sul tasto, ${ }^{4}$ sul ponticello, ${ }^{5} \mathrm{col}$ legno trato, ${ }^{6} \mathrm{col}$ legno battuto, ${ }^{7}$ pizzicato Bartók, ${ }^{8}$ overpressure ${ }^{9}$ e efeitos percussivos, ${ }^{10}$ na atualidade, constituem uma linguagem sonora que não deveria ser de todo estranha aos instrumentistas de cordas. No entanto, métodos, tratados e livros de estudos que protagonizam os currículos de ensino violinístico dificilmente cobrem de forma aprofundada esta área da performance, cujo ensino falho pode resultar na execução ineficaz e no desinteresse de violinistas por grande parte do repertório que lhes é temporalmente mais próximo. Isso ainda pode contribuir para o afastamento entre compositor e intérprete, criando um ciclo que inviabiliza mais ainda uma escrita que seja ao mesmo tempo inovadora e eficaz para o instrumento. Por isso, Padovani e Ferraz (2011) sustentam a necessidade histórica da colaboração entre compositores e instrumentistas e, ao descreverem os processos sonoros dos compositores Berio, Ferneyhough e Lachenmann, ressaltam que

[...] cada vez mais as partituras precisam vir acompanhadas de textos e notas de performance que descrevem não apenas os recursos de notação utilizados, mas também as maneiras de se realizar determinadas técnicas instrumentais/ vocais. Por essa mesma razão, torna-se cada vez mais essencial estabelecer um laço de cooperação entre os compositores e os instrumentistas, marca distintiva da composição com recursos instrumentais estendidos da segunda metade do século XX. (PADOVANI; FERRAZ, 2011, p.29).

Este laço de cooperação pode muito bem ser reforçado, do lado do intérprete, dentro do ensino formal do instrumento através da prática de técnicas presentes no repertório contemporâneo e do desenvolvimento de uma mentalidade receptiva à ino-

20 estudo deste tópico foi tangenciado no desenvolvimento da tese de doutorado do presente autor realizado junto à University of Georgia, sendo aprofundado posteriormente e apresentado aqui na forma de artigo.

3 Na literatura acadêmica brasileira, as expressões "técnica estendida" "e "técnica expandida" são utilizadas de forma equivalente. A palavra "estendida" foi adotada neste artigo, já que a bibliografia mais recente levantada favorece o uso desta.

4 "Sobre oespelho".Indicação para tocarcomo arco sobre o espelho, gerando um som "flautado", pobre em harmônicos agudos.

5 "Sobre o cavalete". Indicação para tocar com o arco sobre ou muito próximo ao cavalete, gerando um som distorcido, com a predominância de harmônicos agudos.

6 Indicação para tocar passando a madeira do arco, ao invés da crina, na corda.

$7 \quad$ Indicação para tocar batendo a madeira do arco na corda.

8 Nome derivado da forte associação desta técnica ao compositor Bèla Bartók. Consiste em uma indicação para realizar o pizzicato puxando a corda de modo que esta bata no espelho ao soltar. É também referido como snap pizzicato, principalmente no contexto da língua inglesa.

9 Indicação para tocar com pressão excessiva, distorcendo o som e possivelmente gerando sub-harmônicos.

10 Sons realizados por meio de batidas no instrumento ou da emulação de sons percussivos. 
vação. ${ }^{11}$ No entanto, o que acontece desde cedo no ensino de instrumento é justamente a negação da legitimidade dos sons "estendidos" (SPOSITO, 2016), ${ }^{12}$ assim como a literatura geralmente considerada como referencial básico para o estudo do violino (como os importantes tratados de Flesch e Galamian, ou Violin Lesson, de Simon Fischer) está claramente defasada neste quesito. Estudiosos da área, como Sarch (1982), Patricia e Allen Strange (2001), Tischhauser (2002) e van der Merwe (2005), já apontaram também para a insuficiência de métodos tradicionais do século $X X$, descendentes das tradições franco-belga, russa e estadunidense, na formação do violinista contemporâneo, dada a emergência de tantos estilos, técnicas e formas de notação musical desde o início daquele século (BUDÓ, 2018, p.4).

Buckles (2003), ${ }^{13}$ no entanto, argumenta que não existe um vazio na literatura didática, mas sim na pesquisa. Ele coloca os livros de estudos de Bohuslav Martinů ( 7 Études rhythmiques-1932), Eugène Ysaÿe (10 Préludes, Op. 35 - 1952), Paul Hindemith (Übungen für Geiger - 1967), John Cage (Freeman Etudes - 1981) e Samuel Adler (Meadowmountetudes - 1996) como referências para capacitar o instrumentista a executar a música da atualidade. Pode ser adicionada àlista parte do trabalho dos famosos pedagogos Galamian e Neumann (1966) ${ }^{14}$ e Rostal (pela sua revisão de Scale System, de Flesch [1987] ${ }^{15}$ ), que também já contribuíram neste sentido incluindo estudos de escalas que incorporam elementos da escrita contemporânea. Estas obras de fato exploram muitos aspectos da linguagem musical moderna que afetam a técnica violinística (intervalos, escalas, arpejos, saltos, ritmos, polirritmos e métrica), no entanto, no que diz respeito a técnicas de produção de som particulares do violino (como os efeitos mencionados no primeiro parágrafo), essas obras se mostram bastante incompletas. Mesmo Buckles, que defende a inexistência de um vazio na literatura didática, conclui que, dentro de sua amostra de livros de estudos pesquisados, técnicas de produção de som são incorporadas apenas em Freeman Etudes, de Cage, uma obra apenas acessível ao instrumentista mais avançado (BUCKLES, 2003, p.204 apudBUDÓ, 2018, p.5).

\footnotetext{
11 Naturalmente, a escrita musical contemporânea não é apenas fundada em técnica estendida ou sequer precisa ter a inovação como um fim, além de que, como o fenômeno complexo que é, não pode ser colocada em uma categoria homogênea. Estes pontos são trazidos aqui simplesmente como elementos presentes neste repertório e que se fazem parte desafiadora da prática violinística atual, no caso de um instrumentista cujo ensino gravitou essencialmente pelos estudos mais tradicionais, associados à música dos séculos XVIII e XIX.

12 Como escreve o autor, " 0 arco muito próximo ao cavalete (sul ponticello), acima do espelho (sul tasto), quase sem pressão (flautato) ou com pressão excessiva, distorcendo o som (écrasé), são sonoridades muito comuns no fazer musical de um aluno iniciante. A correção feita pela maioria dos educadores mostra aos alunos que esse modo de tocar é 'errado"' (SPOSITO, 2016).
}

13 "The void is to be found in the present state of violin literature research. Specifically lacking is the recognition that there appears to be a significant number of contemporary etude books to equip a violinist to successfully perform contemporary music" (Buckles, 2003, p. xii).

14 Na seção "Algumas Escales e Arpejos não Tradicionais", os autores descrevem que "as escalas e arpejos presentes nesta seção foram pensadas como um material introdutório de estudo para a música contemporânea." (GALAMIAN; NEUMANN, 1966, p. 66, tradução minha).

15 Rostal inclui diversos exercícios suplementares pouco comuns em livros tradicionais de escalas e arpejos, incluind o escalas de tons inteiros, quartos de tom, trítonos e pizzicato de mão esquerda, os quais podem ser encontrados nas páginas $121-42$ da edição de 1987. 


\section{DELIMITAÇÃO DO OBJETO DE ESTUDO E METODOLOGIA}

A definição de técnica estendida adotada comumente na literatura parte do que Padovani e Ferraz (2011, p.11) consideram "modos de tocar um instrumento ou utilizar a voz que fogem aos padrões estabelecidos principalmente no período clássico-romântico", ou, de forma mais abrangente, "maneira de tocar ou cantar que explora possibilidades instrumentais, gestuais e sonoras pouco utilizadas em determinado contexto histórico, estético e cultural". Tokeshi (2003, p.53) ainda defende que "recursos tradicionais [...], quando tratados de forma não convencional, também são objeto de estudo de técnica expandida". ${ }^{16}$ Kubala e Tokeshi ilustram esta ideia relacionado o termo

[...] à técnica instrumental demandada por trechos em que ocorre o emprego de variedade de recursos [como tremolo, glissando, harmônicos, alternância métrica, ritmos complexos etc.] em simultaneidade ou em curto espaço de tempo, recursos esses ligados ou não à tradição do instrumento, resultando em escrita complexa e de dificuldade incomum. (KUBALA; TOKESHI, 2016, p.189).

Nesta área, também, comumente os termos "estendida", "não convencional" ou "contemporânea" são utilizados de forma permutável, embora haja técnicas hoje classificadas como "estendidas", por exemplo, col legno battuto, cuja utilização data dos primórdios do período barroco. ${ }^{17} \mathrm{Da}$ mesma forma, diferentes instrumentistas podem considerar determinada técnica como sendo convencional ou não, de acordo com suas próprias experiências. As execuções de intervalos e acordes que exigem padrões muito estendidos ou contraídos da mão esquerda, de ritmos e polirritmos complexos, ou até mesmo de escalas como octatônica, de tons inteiros e acústica, por serem recursos associados à música a partir do século $X X$ (e por trazerem demandas técnicas diferentes daquelas da música dos séculos XVIII e XIX), podem também ser enquadradas por muitos no espectro das técnicas estendidas.

Sendo este tema, portanto, tão abrangente, no presente trabalho optou-se pela criação de quatro categorias de técnicas estendidas para possibilitar um estudo mais detalhado. As categorias propostas aqui são:

1. Técnicas cuja demanda deriva da linguagem rítmica e harmônica característica da música moderna (as quais envolvem uma maneira de se pensar o aprendizado e a expressão musical de uma forma que não é comumente praticada na música até o período romântico em termos do uso de intervalos, acordes, escalas, arpejos, dinâmicas, ritmos, polirritmos e métrica - algo que diz respeito a todos os instrumentos musicais); ${ }^{18}$

2. Técnicas de produção de som específicas do instrumento ${ }^{19}$ (que demandam repensar questões fundamentais da execução do violino especificamente, tais como sul

160 termo "técnica expandida" é usado pela autora como sinônimo de "técnica estendida", sendo esta a forma mais recorrente na atualidade.

17 Padovani e Ferraz (2011, p.14) apontam, por exemplo, a peça de Tobias Hume para viola da gamba intitulada Harke, Harke, do conjunto de peças The First Part of Ayresou Musicall Humors, publicado em 1605, no qual o compositor demanda o uso de técnica análoga a collegno battuto.

18 Pode-se enquadrar aqui também o que Tokeshi (2003, p.53) classifica como recursos tradicionais tratados de forma não convencional.

19 Embora o foco aqui seja o violino, muitas destas técnicas são, na realidade, comuns a todos os instrumentos de cordas friccionadas. 
tasto, sul ponticello, col legno tratto, col legno battuto, pizzicato Bartók. Também é enquadrada aqui a microtonalidade);20

3. Técnicas que envolvem modificações do instrumento (como scordatura, violino preparado, ${ }^{21}$ violinos e arcos estendidos, ${ }^{22}$ uso de amplificação);

4. Combinação da execuçãoviolinística como uso de efeitos vocais, assobios, objetos/instrumentos suplementares, encenação etc.

Esta classificação permite observar de forma mais específica tipos de técnicas presentes na literatura e, por duas razões, optou-se por priorizar a segunda categoria neste estudo, sendo elas: 1) ela envolve questões puramente violinísticas, sem a demanda de recursos especiais; e, 2) em comparação com a primeira categoria (vide trabalhos de grandes compositores, instrumentistas e pedagogos mencionados anteriormente: Hindemithm, Ysaÿe, Adler, Cage, Martinů, Galamian e Rostal), há menos recursos de caráter didático e de conhecimento geral que incluam a segunda.

Os objetivos almejados aqui são o de contribuir para o aprofundamento do estudo de técnicas estendidas e o de promover a união entre prática e ensino das mesmas através da construção de um panorama de recursos textuais e musicais dedicados ao tema. Em termos específicos, buscou-se: trazer à tona obras textuais e musicais sobre técnicas estendidas para violino; constatar as categorias de técnicas existentes em trabalhos; analisar o tipo de abordagem dada ao tema, de acordo com a presença ou não de um enfoque didático; identificar que tipos de recursos didáticos são empregados (se houver).

O estudo seguiu um método de pesquisa exploratória bibliográfica no campo das técnicas estendidas, com ênfase nas técnicas de produção de som. Para tanto, foram buscadas fontes de cunho acadêmico nas línguas inglesa e portuguesa em catálogos como GIL-Find Universal Catalog e WorldCat, bem como nos bancos de dados para teses e dissertações ProQuest e BDTD. As fontes encontradas como resultado desta pesquisa foram divididas entre obras textuais (livros, teses e dissertações) e obras musicais, conforme apresentadas a seguir.

\section{LITERATURA PARA TÉCNICAS ESTENDIDAS DE VIOLINO}

\section{Obras textuais}

\section{Livros}

Um dos volumes mais citados e recorrentes em programas de ensino é o The contemporary violin: extended performance technique (2001), no qual Patricia e Allen

\footnotetext{
20 Pode-se argumentar que o uso de microtonalidade deriva da linguagem harmônica do compositor e não é uma questão específica do violino (pertencendo à categoria 1, portanto); por outro lado, a execução de intervalos como quartos de tom demanda também repensar questões fundamentais da prática (categoria 2), não em termos de timbre, mas de afinação, diferentemente de outras técnicas classificadas na categoria 1, as quais utilizam as mesmas notas e intervalos da música clássico-romântica, só que em um contexto diferente.

21 Entende-se por "preparado" o instrumento no qual são adicionados acessórios não convencionais (grampos presos nas cordas, objetos colocados sobre o tampo etc.) para a modificação de sua sonoridade sem alterar sua construção.
}

Entende-se por "estendido" o instrumento ou arco construídos diferentemente do padrão considerado tradicional na atualidade. 
Strange explanam as mais diversas técnicas com base em repertório de um abundante número de compositores. Parte da série The New Instrumentation, ${ }^{23}$ este volume é dividido em oito capítulos e trata dos assuntos: 1) técnicas de arco; 2) dedos das mãos esquerda e direita; 3) técnicas percussivas; 4) harmônicos; 5) sistemas de afinação; 6) violino preparado, estendido e efeitos diversos; 7) amplificação e processamento de sinais; (8) Midi, cordas e computador. Do ponto de vista didático, esta obra tem grande valor pela inclusão de detalhadas descrições (incluindo sutis variações dentro de uma determinada técnica), todas ilustradas em contexto a partir de exemplos musicais de um vasto repertório. Outro ponto positivo é o enfoque voltado primariamente a técnicas de produção de som, categoria visada aqui, assim como a inclusão de uma discografia referente ao repertório discutido no livro. Entretanto, apesar de apresentar boas recomendações para a execução de muitas das técnicas abordadas, os autores não propõem exercícios, sistemas de estudos e, apesar de haver muitos exemplos musicais das obras citadas, ilustrações de como executar as técnicas são escassamente utilizadas. Steinberg (2002) levanta críticas devido à ausência de comentário sobre como várias técnicas descritas podem afetar adversamente o instrumento e devido ao fato de o volume não trazer um CD para ilustrar o panorama sonoro (embora haja a discografia). Este autor chega a concluir sugerindo que a obra pode ser mais interessante para compositores e musicólogos do que para instrumentistas (STEINBERG, 2002 p.352). Apesar disso, esta certamente permanece sendo a principal referência para o estudo de técnicas violinísticas estendidas.

Uma referência mais recente é The techniques of violin playing, de Irvine Arditti e Robert Platz (2013). Interessantemente, esta obra foi concebida em um formato como se um violinista (Arditti) estivesse aconselhando o compositor (Platz) dentro do tópico das diversas técnicas do instrumento utilizadas na modernidade. O trabalho não é limitado a técnicas estendidas, mas, muito devido à vasta experiência de Arditti com a música contemporânea, inclui uma grande porção destas com exemplos musicais do repertório. Além de conter uma narrativa de colaboração entre compositor e intérprete, dada como essencial por Padovani e Ferraz (2011), este volume chama a atenção também por ser acompanhado por um DVD com demonstrações e comentários de Arditti a respeito de muitas das técnicas abordadas no livro. Apesar de ser uma obra útil para fins de ensino, esta também não é uma obra sistematizada de forma inteiramente didática, posto que, como em The contemporary violin, não há a formulação de estudos e exercícios práticos.

\section{Teses e dissertações}

Além de críticas aos métodos e sistemas tradicionais de ensino, a pesquisa acadêmica na área já rendeu também o desenvolvimento de novos recursos didáticos. Dentre alguns nomes, que inclusive já foram citados, podemos destacar três autores de trabaIhos de pós-graduação especificamente voltados ao ensino de técnicas estendidas: Sar- 
ch (1982), Tischhauser (2002) e van der Merwe (2005). Em The Twentieth Century violin: a treatise on contemporary violin technique, Sarch (1982) traz muitos esclarecimentos sobre o desenvolvimento de uma grande diversidade de técnicas tanto dentro do contexto do repertório violinístico já estabelecido, como através de estudos autorais. Os estudos em geral atendem a uma técnica ou fundamento específico, no formato de pequenas frases, exercícios técnicos, ou peças curtas/miniaturas. Eles estão dispostos ao longo do documento, dentro da seção que discute a técnica correspondente utilizada. São contempladas nesta obra técnicas de execução das quatro categorias estabelecidas, havendo uma grande diversidade de efeitos de produção de som (Fig. 1 e 2).

Study No. 2 - col leqno battuto

a)

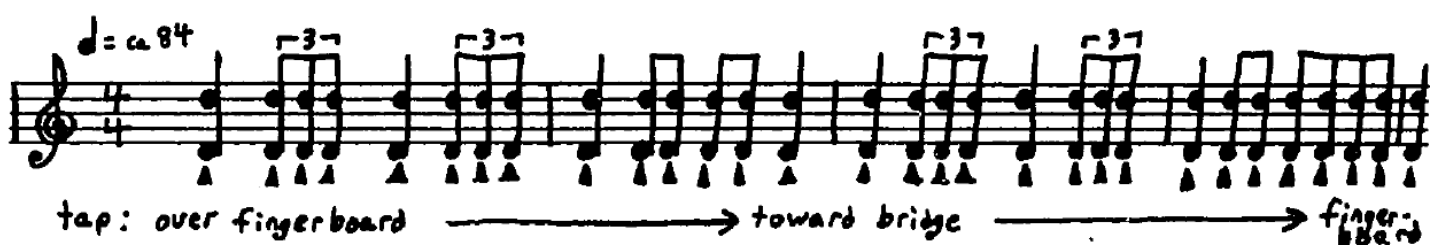

Fig. 1: Estudo n 2 para a técnica col legno battuto. "Bater: sobre o espelho, em direção ao cavalete, espelho". Fonte: Sarch (1982, p.17, tradução minha).

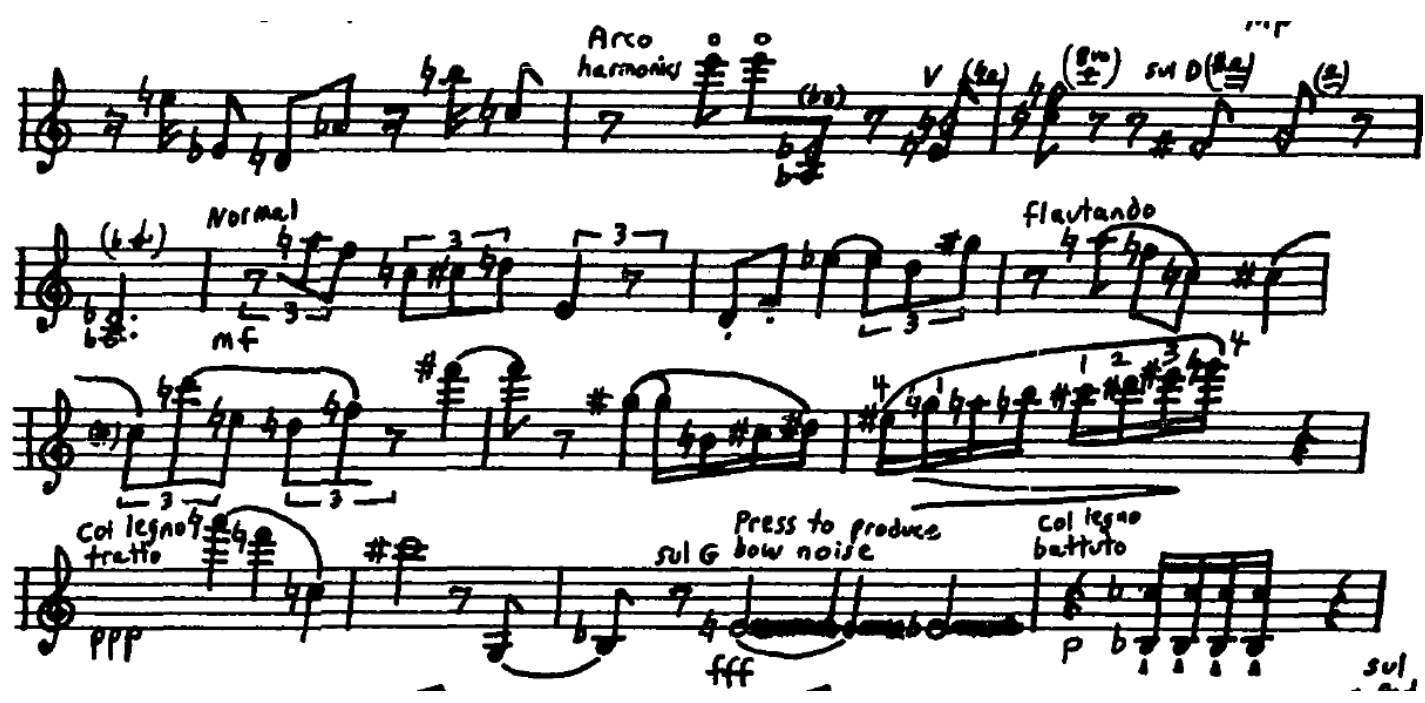

Fig. 2: Estudo n 3, para mudanças súbitas de timbre (compassos 10-24), contendo técnicas de produção de som, como harmônicos, flautando, col legno tratto, col legno battuto, overpressure, além de técnicas associadas à linguagem harmônica moderna, como escala de tons inteiros e deslocamento de oitava. Fonte: Sarch (1982, p.42).

Em sua tese, intitulada "A survey of the use of extended techniques and their notations in Twentieth Century string quartets written since 1933 by american composers with a selected annotated bibliography and discography", ${ }^{24}$ Tischhauser (2002) discute 
o tema dentro de um recorte aparentemente específico (como sugere o título), mas que inclui mais de 100 compositores. Apesar de não ser um trabalho essencialmente pedagógico em sua concepção, o segundo capítulo ("Extended techniques utilized in the Twentieth Century string quartets by american composers") deste documento traz uma extensa compilação de recursos da notação musical moderna (como, por exemplo, na Fig. 3) com uma breve discussão a respeito de sua execução do ponto de vista técnico, servindo como um bom guia prático. Outro ponto interessante é a inclusão de uma bibliografia anotada e discografia do repertório, como o título propõe.

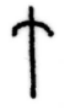

A common notation for playing behind the bridge.

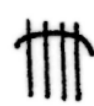

Play behind the bridge on all four strings.

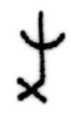

A less common notation for playing behind the bridge.

Another notation for playing behind the bridge.

Fig. 3: Algumas das doze diferentes formas de notação para maneiras de se tocar entre o cavalete e o estandarte do instrumento compiladas pela autora. Fonte: Tischhauser (2002, p.30). ${ }^{25}$

Já o trabalho de Van der Merwe (2005), New frontiers in the art of violin performance: the contemporary study and pedagogy of extended performance techniques for the violin, aborda o tópico a partir da análise de um repertório contendo o violino como parte principal. Ao longo dos três capítulos iniciais, uma grande diversidade de técnicas é discutida, com a utilização de muitos exemplos musicais, mas sem o desenvolvimento de exercícios técnicos. O quarto capítulo, no entanto, consiste em um compêndio de oito caprichos para violino solo compostos pela autora, uma significativa contribuição didática embasada na análise do repertório. Cinco deles cobrem técnicas derivadas da linguagem rítmica e harmônica (categoria 1), sendo elas: harmônicos, mudanças de métrica, deslocamento de oitava, polirritmos, acordes e cordas duplas. Dos demais, um deles envolve scordatura (categoria 3 ), ao passo que outros dois envolvem técnicas de produção de som específicas do violino (categoria 2), sendo um deles para diversos efeitos de timbre (Fig. 4) e o outro para microtons (Fig. 5). A autora também propõe um formato de escala microtonal, incluindo dedilhado e um padrão rítmico para estudo.

nidenses a partir de $1933 \mathrm{com}$ selecionadas bibliografia e discografia anotadas" (TISCHHAUSER, 2002, tradução minha).

25 As explicações de cada símbolo, respectivamente, indicam: "notação comum para se tocar atrás do cavalete"; "tocar atrás do cavalete nas quatro cordas"; "notação pouco comum para se tocar atrás do cavalete"; outra notação para se tocar atrás do cavalete". 


\section{Timbre}

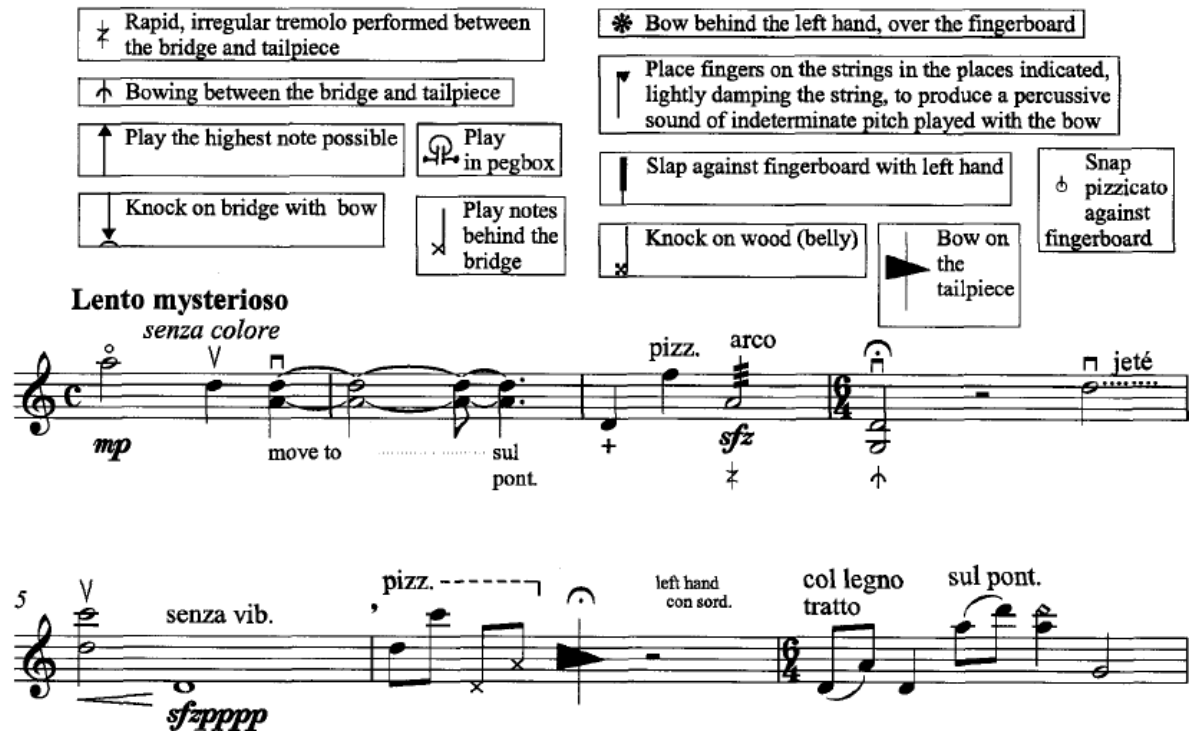

Fig. 4: Capricho intitulado Timbre, contendo uma diversidade de técnicas estendidas com uma breve bula para esclarecer a notação utilizada. Fonte: Van der Merwe (2005, p.171).

\section{Microtones}

\begin{tabular}{|c|c|c|c|c|c|c|}
\hline $\begin{array}{l}\text { d } \\
1 / 4 \text { tone } \\
\text { below } \\
\text { the note }\end{array}$ & $\begin{array}{l}\$ \\
1 / 4 \text { tone } \\
\text { above } \\
\text { the note }\end{array}$ & $\begin{array}{l}\mathrm{db} \\
3 / 4 \text { tone } \\
\text { below } \\
\text { the note }\end{array}$ & $\begin{array}{l}\quad \# \\
3 / 4 \text { tone } \\
\text { above } \\
\text { the note }\end{array}$ & $\begin{array}{l}\text { Pitch inflection } \\
\text { moving a } \\
1 / 4 \text { tone } \\
\text { below the note, } \\
\text { then back to the note }\end{array}$ & $\begin{array}{l}\text { Pitch inflection } \\
\text { moving a } \\
1 / 4 \text { tone } \\
\text { above the note, } \\
\text { then back to the note }\end{array}$ & $\begin{array}{l}\text { Wide quarter-tone vibrato } \\
\text { that increases in intensity } \\
\text { and width through the note }\end{array}$ \\
\hline
\end{tabular}

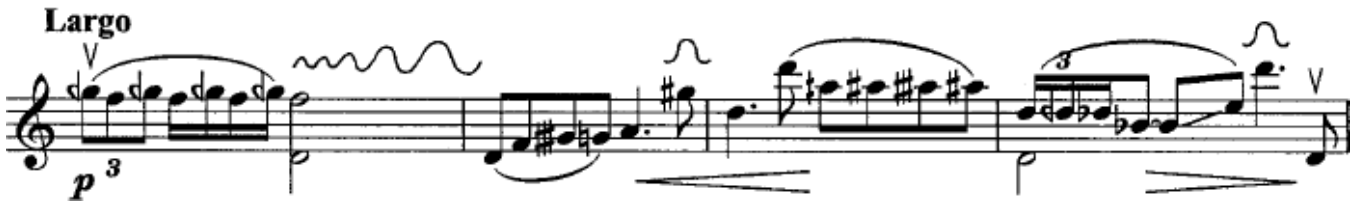

Fig. 5: Capricho intitulado Microtones, no qual são explorados quartos de tom, conforme a explicação dos símbolos acima. Fonte: Van der Merwe (2005, p.179).

Como pode se esperar de trabalhos de autores baseados na Europa e nos Estados Unidos, como os mencionados até aqui, o foco está geralmente no repertório de compositores provindos ou radicados nos países desse eixo. Mesmo a obra mais inclusiva, The contemporary violin, analisa obras de uma quantidade esmagadoramente maior de compositores europeus e estadunidenses, comparada ao número de nomes de outras regiões. Por outro lado, no Brasil, pesquisas na área foram impulsionadas nas últimas décadas com o foco no repertório composto por brasileiros. Alguns dos estudos mais citados incluem o artigo "Técnica expandida para violino e as variações opcionais de Guerra-Peixe: reflexão sobre parâmetros para interpretação musical" (TOKESHI, 2003) e o trabalho apresentado em congresso da Anppom "Técnica expandida para violino: classificação e avaliação de seu emprego na música brasileira" (COPPETI; TOKESHI, 
2005). Interessantemente, o tópico tem sido explorado também em teses e dissertações de diferentes formas nos últimos cinco anos, como visto nos trabalhos de Lôbo (2016), Rufino (2017), Budó (2018) e Krewer (2019), sendo os três últimos, no entanto, escritos na língua inglesa.

Em consonância com a já mencionada proposta de aproximação entre intérprete e compositor de Padovani e Ferraz (2011), o violinista Lôbo (2016) escreveu "Composição e intérprete: reflexões sobre processo criativo em Caminho Anacoluto II - quasi-Vanitas de Marcílio Onofre", dissertação de mestrado na qual justamente descreve a maneira como colaborou com o compositor, Onofre, na criação da referida peça para violino e piano. Apesar de não ser parte central da dissertação, foram dedicadas seções para a discussão da "Técnica Expandida" de uma forma geral (LÔBO, 2016, p.21-26), bem como, mais especificamente, "O violino e sua expansão técnica em Caminho Anacoluto II" (LÔBO 2016, p.39-45). O trabalho contém uma boa contextualização de técnicas não tão recorrentes, tais como pizzicato com a unha, pizzicato atrás do cavalete, tonlos, ${ }^{26}$ bow in the instrument body, ${ }^{27}$ silent fingering ${ }^{28} \mathrm{e}$, provavelmente a mais curiosa ce todas, "cuíca"29 (todos os nomes mantidos como utilizados pelo compositor). A Fig. 6 ilustra uma passagem que contém a notação do compositor para algumas das técnicas discutidas na obra.

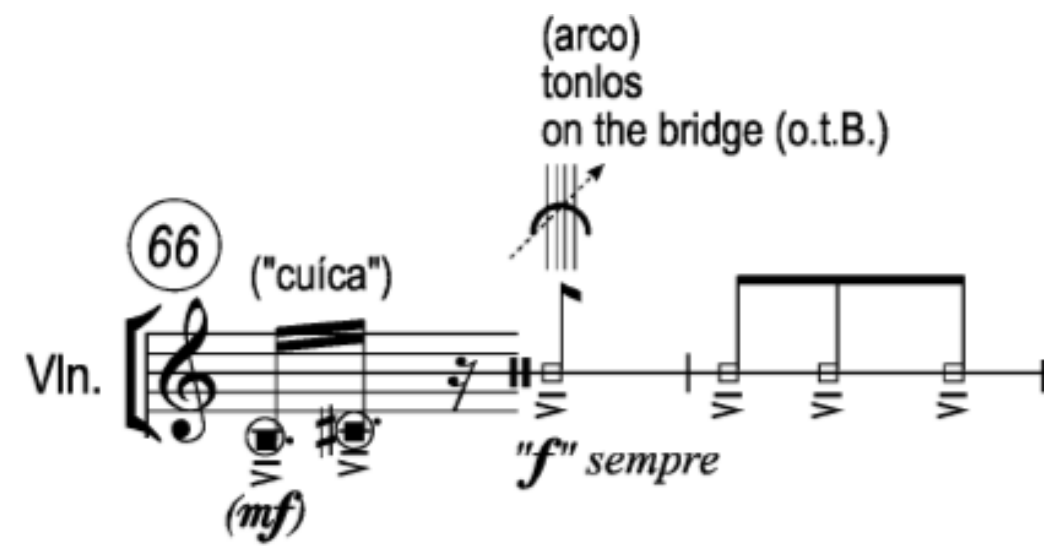

Fig. 6: Excerto de "Caminho Anacoluto II", de Marcílio Onofre, com a utilização de duas das mencionadas técnicas. Fonte: Lôbo (2016, p.69).

Caminho Anacoluto II, de Onofre, foi também material de estudo de Rufino (2017), cujo trabalho de doutorado foi intitulado "Styles and extended techniques in 6 works for violin from Paraíba since 1952". Apesar de ser textualmente modesta, a obra de Rufino tem um excelente aspecto: a produção de uma gravação em estúdio de todo o reper-

\footnotetext{
26 Do alemão: tonlos = "sem som". Indicação para passar o arco (possivelmente de forma oblíqua) pelas cordas abafadas com a mão esquerda, de modo a não gerar notas definidas (nem mesmo por harmônicos).

27 Do inglês, "passar o arco no instrumento". 0 autor não clarifica, porém, maiores detalhes.

28 Do inglês, "dedilhar silenciosamente". Bater os dedos da mão esquerda na corda sem utilizar o arco.

29 Esta técnica demanda que um fio de crina seja amarrado na corda sol do instrumento, sendo o som produzido através da fricção dos dedos indicador e polegardeslizando porestefio, de forma análoga ao processo de produção de som em uma cuíca (LÔBO,2016,p.33).
} 
tório estudado, a qual pode ser acessada on-line ${ }^{30}$ e que, segundo o autor, "representa o primeiro álbum inteiramente dedicado ao repertório violinístico da Paraíba" (RUFINO, 2017, p.24). A parte escrita do trabalho, assim como em muitos outros casos explorados aqui, não é fundamentalmente didática e se restringe a uma breve lista com as notações e descrição das técnicas estendidas utilizadas em duas das obras gravadas: Lágrimas de Oort, de Ticiano Rocha, para violino solo; e, como já mencionado, a peça de Onofre. Por não conter técnicas estendidas per se, o restante do repertório foi analisado mais em termos de métodos composicionais e estilo, na maioria associados ao folclore nordestino brasileiro.

Dois outros trabalhos, Budó (2018) e Krewer (2019), propõem-se diretamente a sanar algumas lacunas didáticas da literatura. Intitulado "Analysis of uncompiled extended violin techniques with didactic musical and audiovisual examples”, Budó enfoca o aprendizado de técnicas pouco visadas em compilações do gênero, como técnicas do tango argentino, do folk norte-americano e da música de concerto brasileira. ${ }^{31}$ Esta tese foi concebida através de uma perspectiva didática do ponto de vista do músico classicamente treinado, contendo, além da descrição das técnicas em seu contexto, novas experimentações com elas. São apresentados exemplos musicais, figuras, exercícios (Fig. 7), recursos audiovisuais (acessíveis via link para vídeo disponibilizado no YouTube) e uma seleção de quatro caprichos autorais utilizando as técnicas discutidas (Fig. 8).

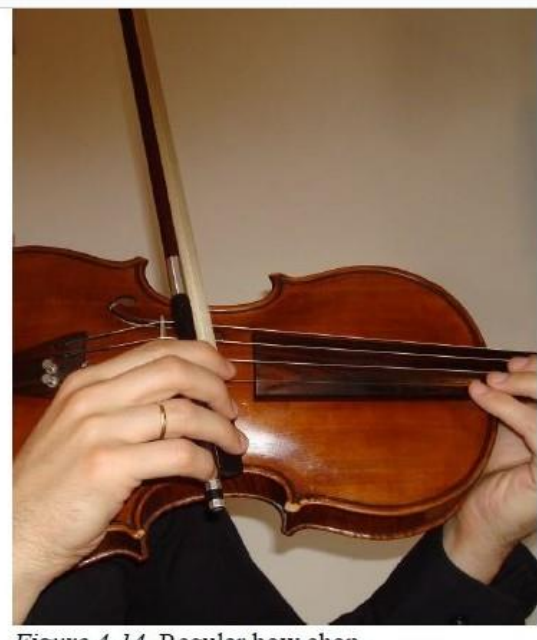

Figure 4-14. Regular bow chop.

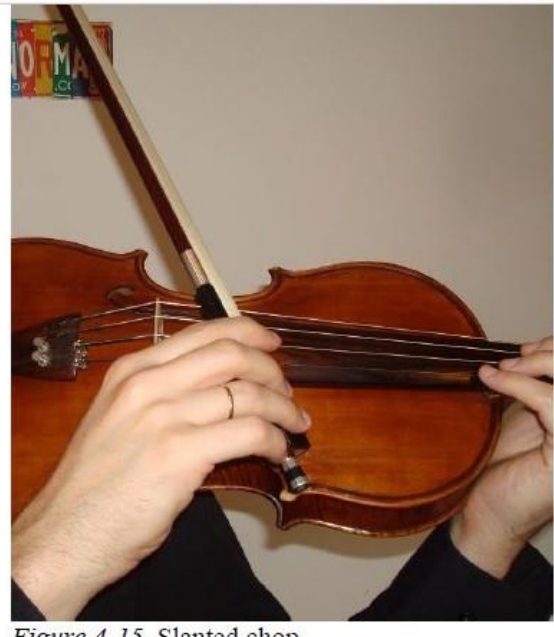

Figure 4-15. Slanted chop.

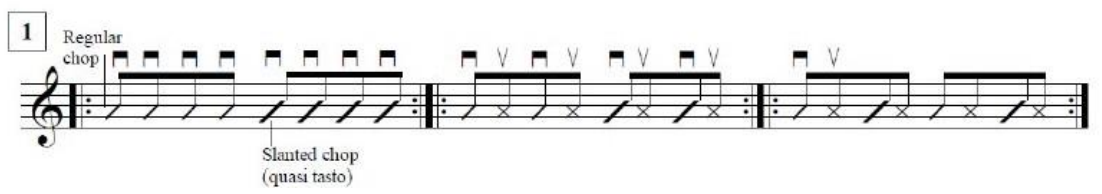

Fig. 7: Exercício para a execução de bow chops, articulação percussiva característica do bluegrass norte-americano. ${ }^{32}$ Fonte: Budó (2018, p.58).

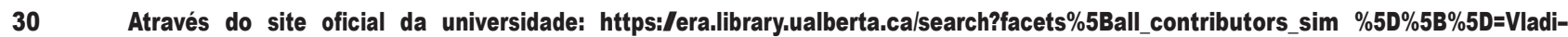
mir+Rufno; ou no YouTube, onde todas as faixas foram disponibilizadas pelo canal "Vladimir Rufino" e podem ser facilmente localizadas através das palavras-chave correspondentes.

31 É também discutido o tema de harmônicos em terça menor nos caprichos de Salvatore Sciarrino, obra que, em contraste com o restante do repertório, é muito mencionada na maioria dos estudos de técnicas estendidas.

Vídeo com a demonstração deste exercício disponível em: https://youtu.be/kG1HAQndggc. 


\section{8}

Caprice for "cuíca" effects

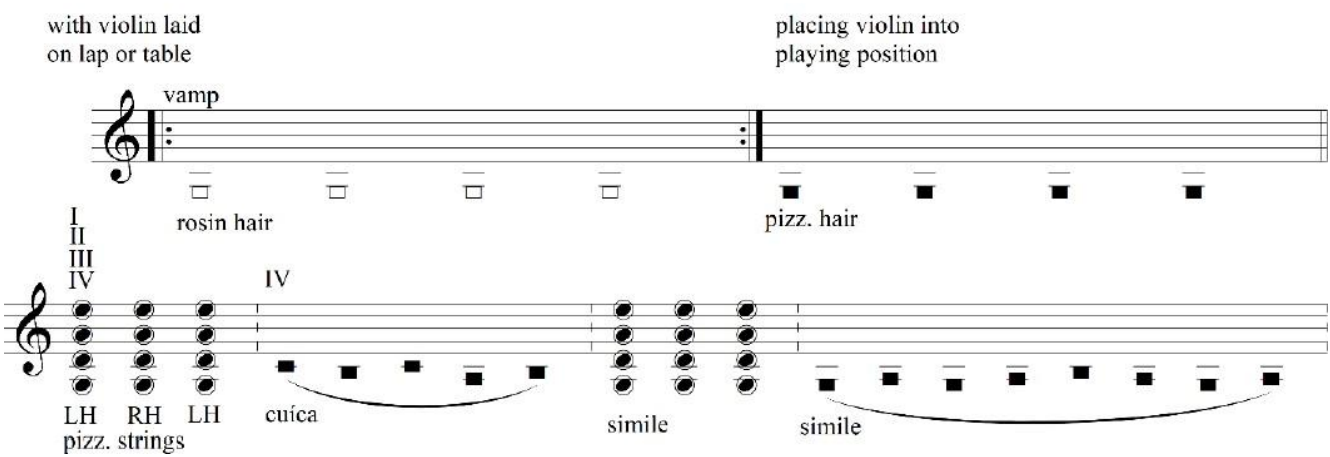

Fig. 8: Capricho explorando possibilidades diversas a partir da técnica "cuíca". Fonte: Budó (2018, p.90).

Krewer, por outro lado, procurou sanar a ausência de recursos didáticos para alunos intermediários, posto que "a maior parte do material é direcionado para estudantes avançados ou instrumentistas profissionais" (KREWER, 2019, p.ix). Na tese "Extended techniques for intermediate violin students", a autora analisa técnicas recorrentes no repertório divididas em duas grandes categorias: mão direita e mão esquerda. A partir desta análise, são descritas formas de se praticar as determinadas técnicas. Alguns exercícios autorais são propostos (Fig. 9), bem como é sugerida a prática através de passagens do repertório (Fig. 10). Diferentemente das demais obras por autores brasileiros, esta não visa o repertório nacional em especial e atém-se principalmente a exemplares provindos da Europa.
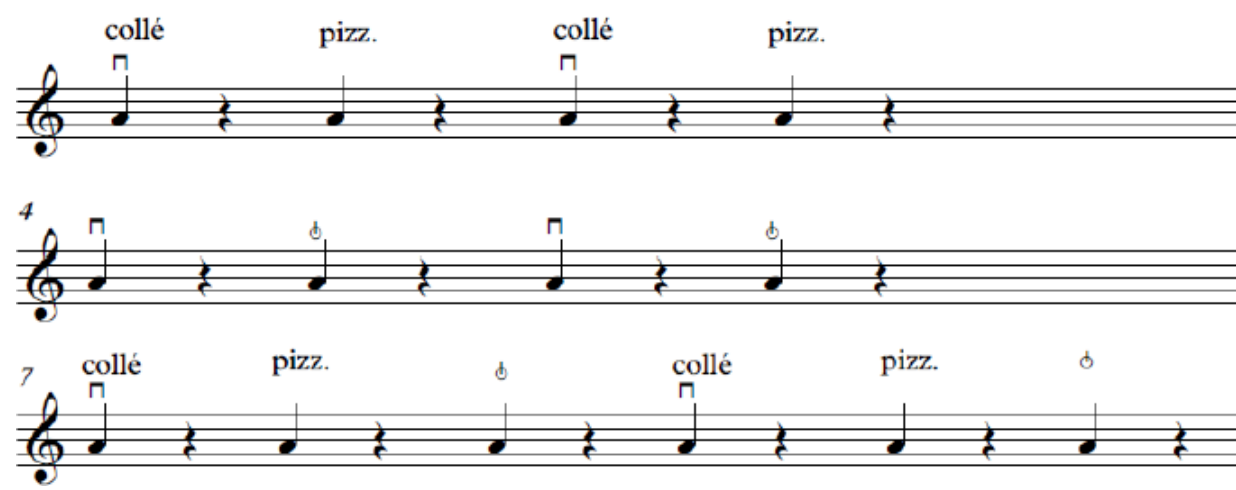

Fig. 9: Exercício para alternância entre posições de arco e pizzicato. Fonte: Krewer (2019, p.91).

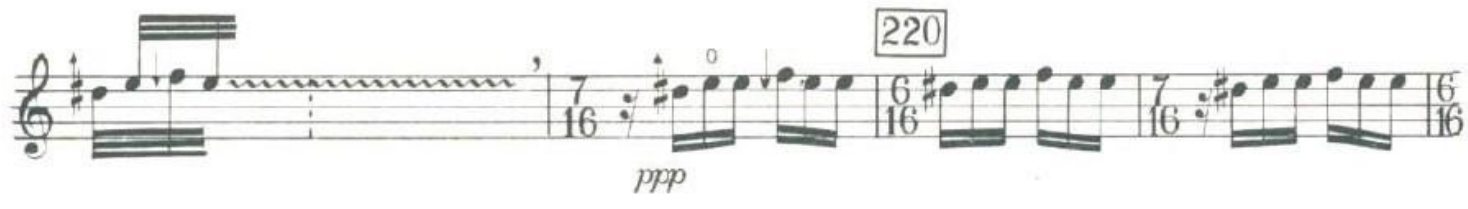

Fig. 10: Excerto do terceiro movimento da Sonata de Karel Husa proposto como exercício para a prática de quartos de tom. Fonte: Krewer (2019, p.51). 
Constata-se, então, que há uma considerável produção de obras textuais, especialmente nos últimos vinte anos, com alguma contribuição didática, embora nem todas tenham sua concepção centrada no ensino do instrumento, como é o caso de Patricia e Allen Strange (2001), Tischhauser (2002) e Arditti e Platz (2013). Os trabalhos de Lôbo (2016) e Rufino (2017), apesar de não terem o ensino do instrumento e técnicas estendidas como objeto principal de estudo (posto que abrangem outros assuntos, sendo técnicas estendidas um subtópico), são, por sua vez, fontes com informações relevantes sobre o tema, bem como trazem destaque ao repertório nacional. Quatro outras obras incluem a produção de exercícios ou estudos práticos, sendo que Krewer (2019) atém-se a exercícios técnicos, Van der Merwe a estudos musicais, ao passo que Sarch (1982) e Budó (2018) incorporam ambos os modelos.

O uso de imagens, historicamente praticado em obras para o ensino do instrumento para fins de ilustrar como executar determinadas técnicas do ponto de vista postural, não é algo recorrente na amostragem analisada aqui. A demonstração sonora, algo mencionado na contundente crítica de Seinberg (2002) à obra de Patricia e Allen Strange (2001), é algo com que alguns dos autores se preocuparam, trazendo discografias e (em obras mais recentes) incorporando mídias sonoras ou audiovisuais ao trabalho. $O$ desenvolvimento tecnológico, principalmente na última década, propicia isto com mais facilidade, mas ainda não é uma prática comum em trabalhos de cunho acadêmico. A Tab. 1 apresenta uma análise comparativa dos conteúdos encontrados em cada uma das obras textuais discutidas anteriormente.

\begin{tabular}{|l|l|l|l|l|l|}
\hline & $\begin{array}{c}\text { Exemplos do } \\
\text { repertório }\end{array}$ & $\begin{array}{c}\text { Exercícios/ } \\
\text { estudos }\end{array}$ & $\begin{array}{c}\text { Ilustrações } \\
\text { para execução }\end{array}$ & $\begin{array}{c}\text { Recursos } \\
\text { auditivos ou } \\
\text { audiovisuais }\end{array}$ & Discografia \\
\hline Sarch (1982) & & & & & \\
\hline P. Strange e A. Strange (2001) & & & & & \\
\hline Tischhauser (2002) & & & & & \\
\hline Van der Merwe (2005) & & & & & \\
\hline Arditti e Platz (2013) & & & & & \\
\hline Lôbo (2016) & & & & & \\
\hline Rufino (2017) & & & & & \\
\hline Budó (2018) & & & & & \\
\hline Krewer (2019) & & & & \\
\hline
\end{tabular}

Tab.1: Obras textuais conforme a inclusão de elementos de caráter didático. Fonte: Elaborado pelo autor (2020).

Os tipos de técnica e repertório abordados nas obras também variam de acordo com o autor. Como se pode ver na Tab. 2, as obras textuais tratam técnicas estendidas de três formas: 1) dentro do âmbito da técnica violinística em geral; 2) como um assunto em si, tratado de uma forma geral, porém separado da técnica violinística tradicional; 3) com base na sua utilização dentro de um repertório ou gênero específicos, limitando-se às técnicas presentes nestes. 


\begin{tabular}{|l|l|l|l|}
\hline & $\begin{array}{c}\text { Inclui técnicas } \\
\text { estendidas dentro } \\
\text { do âmbito da técnica } \\
\text { violinística em geral }\end{array}$ & $\begin{array}{c}\text { Trata de técnicas } \\
\text { estendidas de modo } \\
\text { geral }\end{array}$ & $\begin{array}{c}\text { Trata de uma seleção } \\
\text { específica de técnicas de } \\
\text { acordo com um reper- } \\
\text { tório e/ou gênero(s) } \\
\text { selecionado(s) }\end{array}$ \\
\hline Sarch (1982) & & & \\
\hline P. Strange e A. Strange (2001) & & & \\
\hline Tischhauser (2002) & & & \\
\hline Van der Merwe (2005) & & & \\
\hline Arditti e Platz (2013) & & & \\
\hline Lôbo (2016) & & & \\
\hline Rufino (2017) & & & \\
\hline Budó (2018) & & & \\
\hline Krewer (2019) & & & \\
\hline
\end{tabular}

Tab. 2: Obras textuais de acordo com os tipos de técnica e repertório abrangidos. Fonte: Elaborado pelo autor (2020).

Existe também uma predominância de trabalhos que utilizam técnicas primariamente da música de concerto de compositores europeus e norte-americanos, com as exceções de Lôbo (2016) e Rufino (2017), os quais deliberadamente optaram por estudar exemplares do repertório brasileiro de concerto, bem como Budó (2018), que, além disso, traz um enfoque também nas técnicas do tango argentino e da música folk norte-americana.

\section{Obras musicais}

Dentre o repertório de natureza didática, uma interessante fonte provém de uma comissão da American String Teacher Association (ASTA) para construir uma ponte entre literatura tradicional de ensino e música contemporânea, a qual resultou na publicação 16 contemporary violin etudes for study and performance (1982). Editada pelo violinista Eugene Gratovich, a obra é formada por estudos musicais escritos pelos compositores Allan Blank, Ralph Shapey, George Flynn e Virko Baley (sendo quatro estudos de cada compositor). As peças exploram as mais diversas técnicas utilizadas na música contemporânea, indo do relativamente simples ao extremamente complexo.

Os estudos de Blank e Shapey demandam uma habilidade considerável do instrumentista, apesar de serem certamente os mais didáticos e acessíveis. Blank baseou grande parte do conteúdo técnico de seus quatro estudos em duas obras suas (Music for solo violin [1961] e Music for solo violin [1972]) (GRATOVICH, 1982, p.4), sendo que os três primeiros lidam primariamente com alternância entre intervalos e padrões de mão esquerda, tanto de forma melódica (estudos I e II) quanto harmônica (estudos I e III), contendo principalmente muitas contrações de mão esquerda. O quarto estudo incorpora a isto acordes e efeitos variados de articulação e timbre, como harmônicos, tremolo, sul tasto/ponticello, pizzicato, sendo assim o único deste compositor a incluir técnicas categorizadas como de produção de som específicas do violino (Fig. 11). O compositor também inclui um exercício preparatório de alternância de padrões de mão 
esquerda (Fig. 12) em preparação ao estudo II, o qual é recomendado por Gratovich como ponto de partida para a prática de todas as obras do livro.

\section{Mixtures}

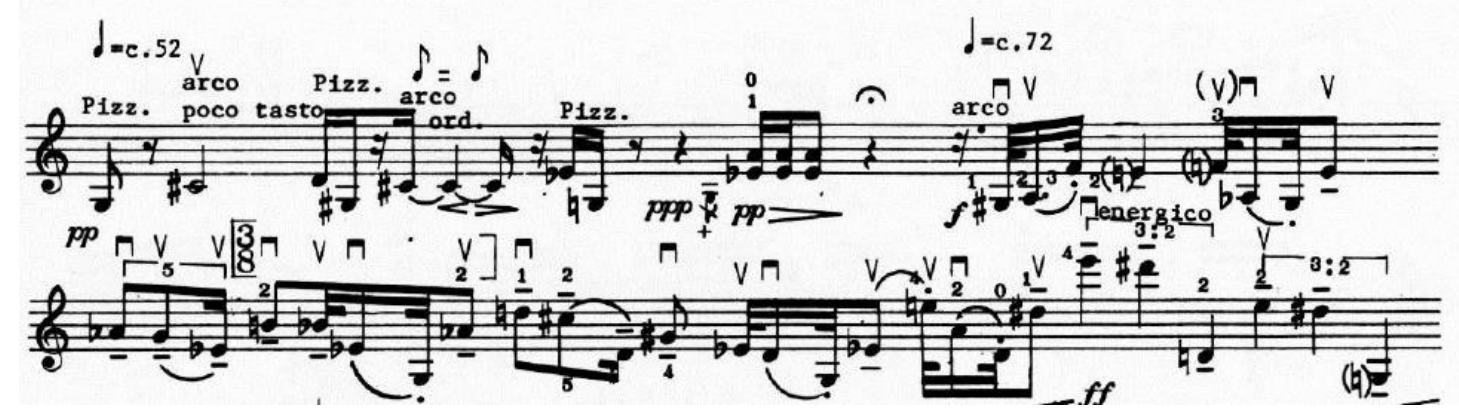

Fig. 11: Estudo de Blank (1982) intitulado Mixtures, com técnicas variadas. Fonte: Gratovich (1982 p.13).

II.

2. Double Stops

Preparatory Exercise:

In addition to double stop scales at various intervals the following expanding

or contracting patterns are suggested. Transpose and add bowing and rhythmic variants:

(a) EXPANDING $\quad$ (b) CONTBACTING Retrograde in C.

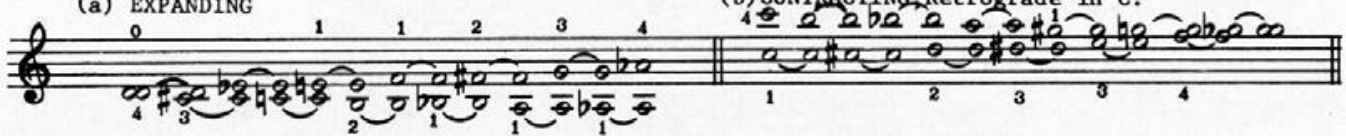

Fig. 12: Exercício preparatório de alternância de padrões de mão esquerda proposto por Blank (1982).

Fonte: Gratovich (1982 p.10).

Dentre outras habilidades técnicas características da modernidade, os estudos de Shapey enfatizam intervalos/acordes dissonantes, extensões e especialmente grandes mudanças de registro, demandando muitas vezes a execução de posições altas em cordas graves (Fig. 13). Para este estudo, Gratovich desenvolveu uma série de exercícios (Fig. 14) para saltos de mão esquerda e para execução de intervalos/acordes dissonantes e com extensões. Estes quatro estudos enquadram-se, portanto, na categoria de técnicas violinísticas derivadas da linguagem harmônica e rítmica do compositor, ou seja, explorando a sonoridade usual do instrumento, mas com combinações de notas e ritmos não característicos dos estilos dos séculos XVIII e XIX.

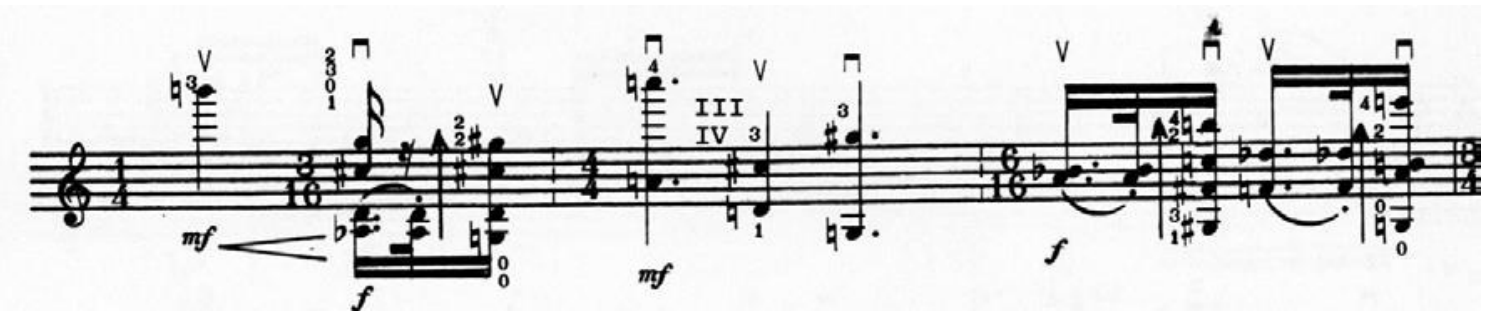

Fig. 13: Estudo III de Shapey (1982), compassos 5-8. Fonte: Gratovich (1982 p.21). 


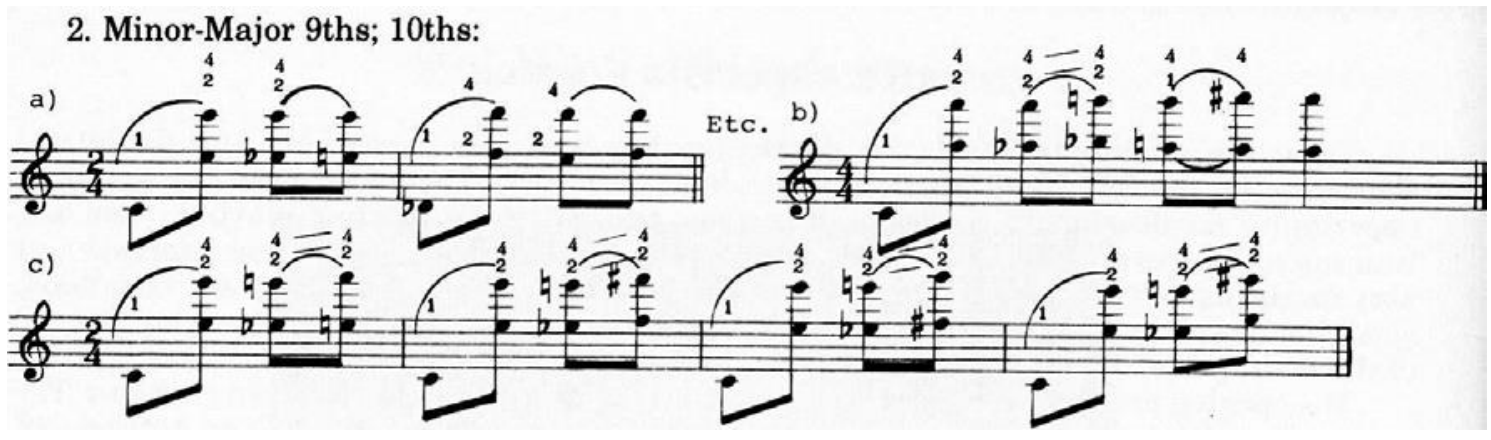

Fig. 14: Alguns dos exercícios preparatórios para saltos de mão esquerda, execução de intervalos/acordes dissonantes e extensões para a execução dos estudos de Shapey (1982). Fonte: Gratovich (1982 p.18).

Pode-se dizer que os quatro estudos de Flynn, intitulados pelo compositor Four fantasy-etudes for violin, priorizam respectivamente: I) intervalos melódicos e harmônicos dentre a complexa mistura métrica e rítmica e com incidência de quartos de tom; II) harmônicos, sendo uma grande quantidade destes em cordas duplas, com a ocorrência de glissando e sul ponticello; III) acordes quebrados e arpejados, como uma "expansão moderna da técnica de acordes encontrados na Ciaccona de Bach"33 (GRATOVICH, 1982, p.30, tradução minha); IV) caráter improvisatório através de rubato escrito, contendo uma segunda voz que, somada à primeira, resulta em diversos polirritmos e pode ser executada por outro violino, viola, ou mesmo por uma gravação prévia do mesmo violinista. De modo geral, pode-se dizer que estes estudos se encontram em um nível maior de dificuldade tanto pela demanda mais complexa de habilidades técnicas quanto pela duração consideravelmente mais longa deles, dando a este conjunto um caráter mais concertante do que de estudo. De fato, Flynn descreve que "o valor principal deles deve ser visto como musical e não somente técnico"34 (GRATOVICH, 1982 p.29, tradução minha) (Fig. 15).

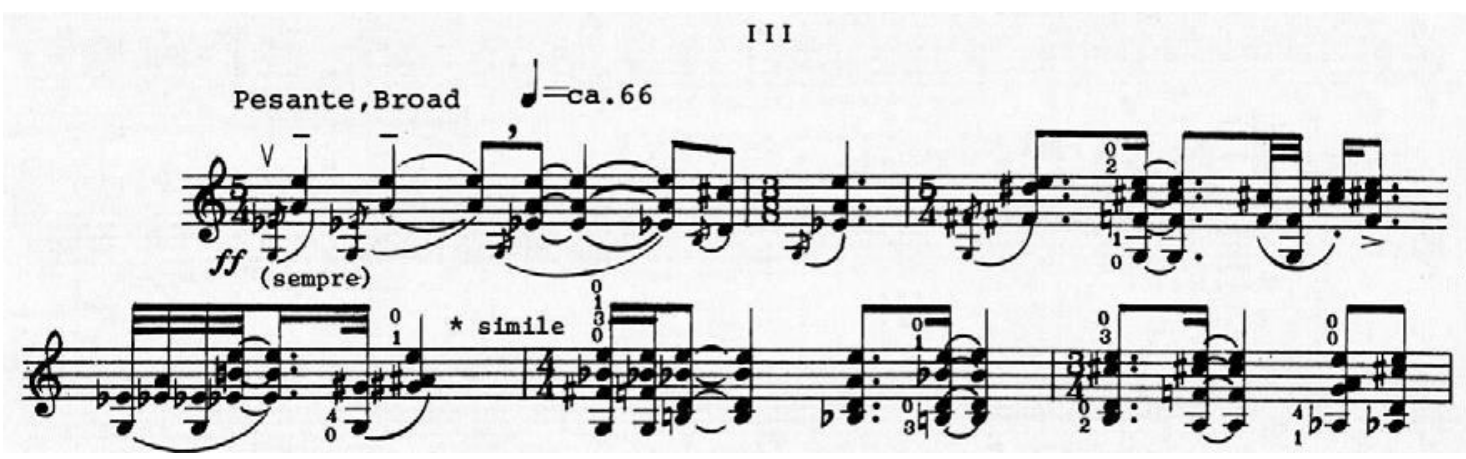

Fig. 15: Estudo III de Flynn (1982). Fonte: Gratovich (1982 p.38).

Na mesma linha de Flynn, Baley demonstra certa preocupação com a valorização musical de sua obra, escrevendo que esta constitui "uma suíte de estudos e não exercícios. Eles continuam a tradição dos caprichos de Paganini e não a de estudos 
de Ševčík" (GRATOVICH, 1982 p.54, tradução minha). ${ }^{35}$ Este conjunto de peças foi intitulado ...figments e, posteriormente, foi ampliado pelo compositor, formando uma suíte $^{36}$ homônima de seis movimentos. Os estudos presentes neste livro são intitulados: I. Sonant...; II. Kolomyika, a dance...; III. Chorale... (Parastas); IV. Perpetuo mobile. A intenção primária de Baley nesta obra é a de expandir a performance violinística para muito além do tradicional, incorporando desde efeitos de produção de som mais tradicionais, como pizzicato Bartók e sul ponticello, passando por uma gama de formas de percussão no instrumento e chegando até a utilizar efeitos vocais e assobios. Para tal, uma longa bula explicativa é apresentada com minúcias a respeito dos diversos efeitos desejados. Os estudos de Baley demandam um exercício dos mais complexos em termos de coordenação, afora que a notação pode parecer bastante confusa a princípio devido ao uso de um sistema com diversas pautas representando diferentes efeitos (ver Fig. 16).

\section{CHORALE , .. (PARAstas)}

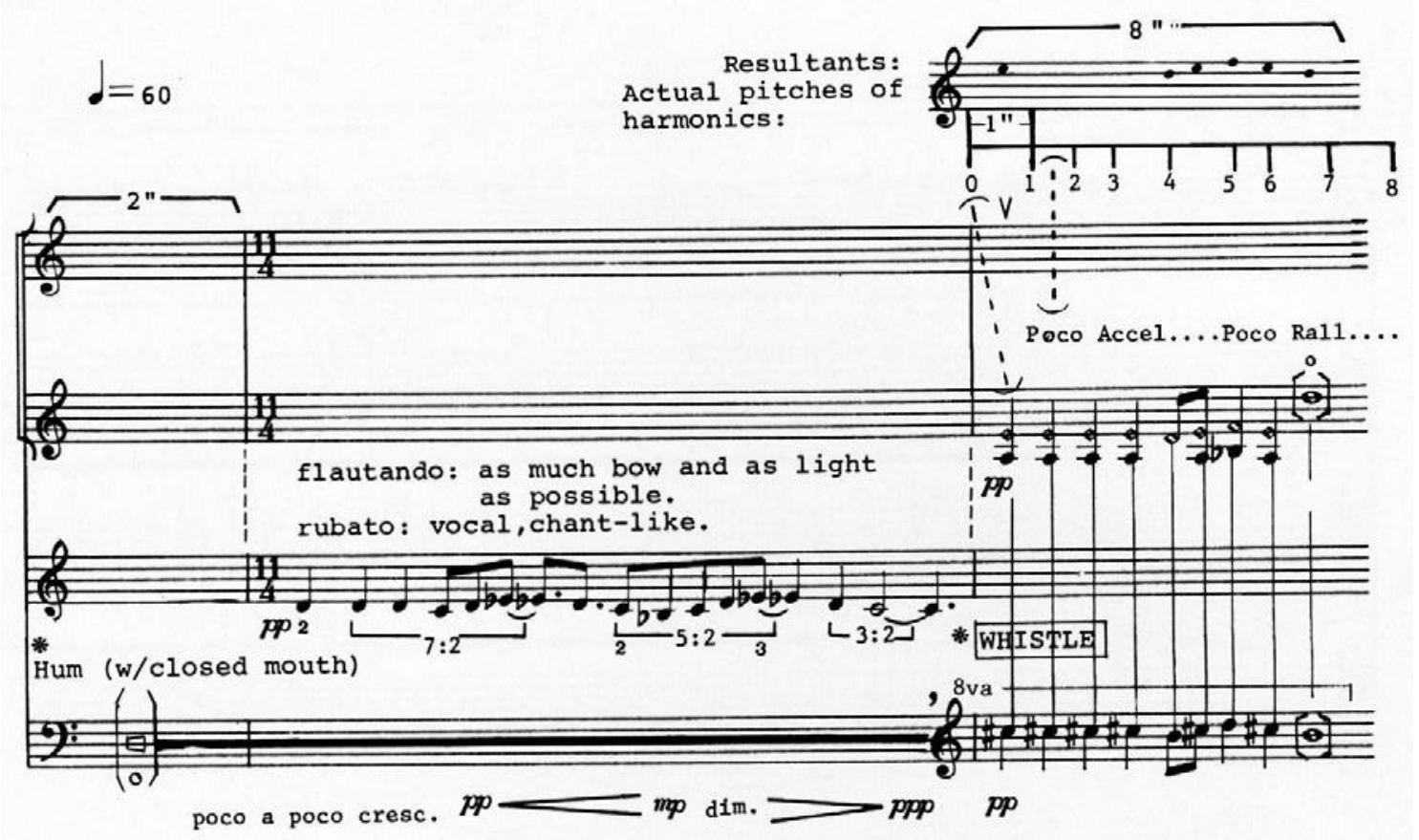

Fig. 16: Partitura do terceiro estudo de Baley (1982), incluindo efeitos vocais nos compassos 1-2 e assobio no terceiro. Fonte: Gratovich (1982 p.69).

Afora os estudos em si, 16 contemporary violin etudes também traz uma variedade de observações realizadas tanto pelos compositores quanto pelo editor que são de grande valor para o entendimento da prática performática e processos composicio-

35 Original: "[...] a suite of etudes and not exercises. They continue the tradition of Paganini Caprices and not of Sevcik studies" (GRATOVICH, 1982 p.54).

36 Na suíte, foram adicionados os movimentos III e VI, sendo todos colocados na seguinte disposição: I. sonant...; II. Chorale (Parastas)...; III Feux Follets...; IV. Kolomyika, a Dance...; V. Perpetuo Mobile...; VI. Passacaglia. 
nais da modernidade. Além de exercícios técnicos já mencionados para o preparo de alguns estudos, Gratovich inclui também um apêndice rico em conselhos e ideias de como pensar e praticar fundamentos técnicos recorrentes em música do final do século XX, como treinamento auditivo e rítmico, identificação de padrões cromáticos de mão esquerda, escalas, arpejos, cordas duplas e coordenação em geral. Esta parte do livro pode ser até mais interessante ao instrumentista intermediário ou pouco familiarizado com o repertório contemporâneo do que os estudos em si.

Dentro do repertório didático enquadram-se também Duetti per due violini, de Luciano Berio (1979-1983). A exemplo dos 44 duetos de Bartók (1933), estes foram também compostos com um fim educacional em mente, sendo em sua maioria curtos (muitos com menos de um minuto de duração), e foram colocados de forma progressiva em termos de dificuldade. Cada um dos 34 duetos leva o nome de um compositor, havendo, segundo Berio, "razões e situações pessoais" por detrás de cada um deles (BERIO). Grande parte pode ser tranquilamente executada desde um nível intermediário e alguns são até mesmo adequados para iniciantes. Muitos elementos composicionais da música do século XX são empregados, sendo que 16 duetos incluem efeitos de produção de som, limitados, no entanto, apenas a sul tasto (no 1, 13, 15, 18, 30 e 34) e sul. ponticello ( $\mathrm{n}=1,5,9,11,12,14,20,23,24,30,32$ e 34), havendo uma rara ocorrência de col legno ( $\mathrm{n}^{\circ}$ 20) (ver Fig. 17).

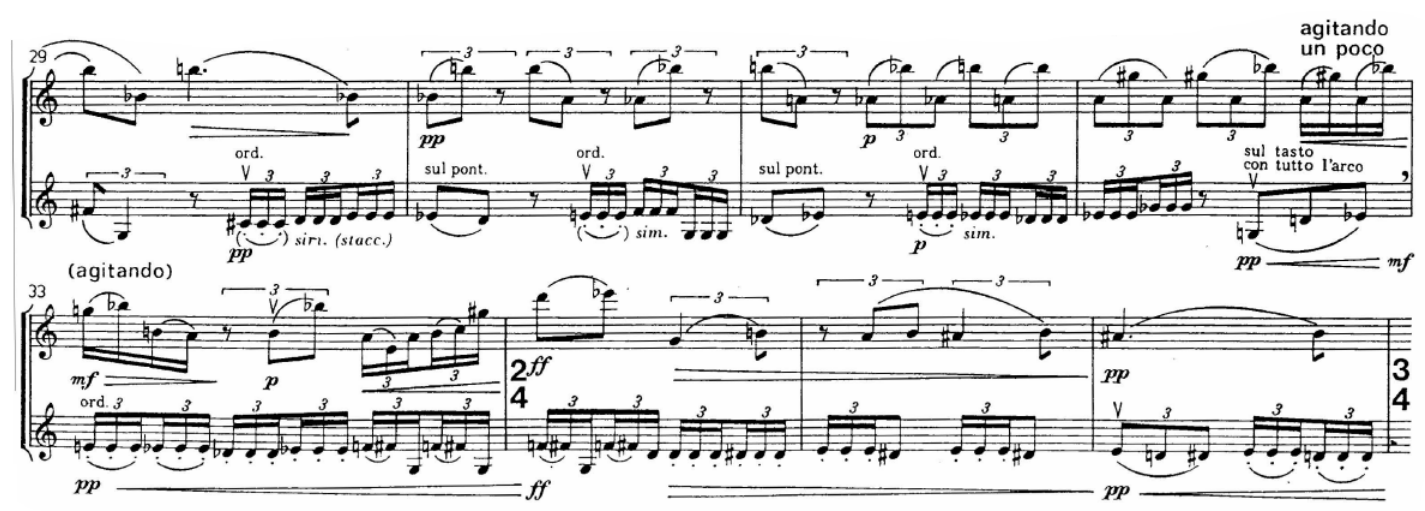

Fig. 17: Trecho do dueto $n^{\circ} 30$ (Massimo), onde se pode- observar o uso das técnicas sul ponticello e sul tasto na parte de segundo violino. Fonte: Berio (1983, p.51).

Diferentemente do caso das obras musicais de Martinů (1932), Ysaÿe (1952), Hindemith (1967), Cage (1981) e Adler (1996), não se encontram disponíveis muitas gravações das obras discutidas aqui. Foi encontrada apenas uma gravação parcial de 16 contemporary violin etudes, com a execução do próprio editor, Gratovich, no álbum 20 th century concert études for solo violin com selo da Titanic Records. Constam neste registro (pela ordem das faixas) os três primeiros estudos de Flynn, Baley e Shapey, bem como os estudos 4, 1 e 2 de Blank. A respeito dos duetos de Berio, há diversas gravações (em distintos níveis de qualidade) de seleções de estudos publicadas no YouTube, no entanto, há uma gravação da série completa de duetos lançada em 2016 como parte do álbum do violinista Joseph Puglia, intitulado Ladder of escape 14, pela gravadora Attacca Productions. 
De acordo com as quatro categorias de técnicas estendidas propostas neste estudo (vide a seção "Delimitação do objeto de estudo e metodologia"), pode-se mapear a abrangência das obras mencionadas aqui de acordo com a Tab. 3.

\begin{tabular}{|l|l|l|l|l|}
\hline & Categoria 1 & Categoria 2 & Categoria 3 & Categoria 4 \\
\hline $\begin{array}{l}\text { *Martinů (1932) Études rhythmiques } \\
\text { "Ysaÿe (1952) } \\
10 \text { Préludes, Op. 35 }\end{array}$ & & & & \\
\hline $\begin{array}{l}\text { *Hindemith (1967) } \\
\text { Übungen für Geiger }\end{array}$ & & & & \\
\hline $\begin{array}{l}\text { *Cage (1981) } \\
\text { Freeman Etudes }\end{array}$ & & & & \\
\hline $\begin{array}{l}\text { Blank (1982) } \\
16 \text { Contemporary Violin Etudes (1-4) }\end{array}$ & & & & \\
\hline $\begin{array}{l}\text { Shapey (1982) } \\
16 \text { Contemporary Violin Etudes (5-8) }\end{array}$ & & & & \\
\hline $\begin{array}{l}\text { Flynn (1982) } \\
16 \text { Contemporary Violin Etudes (9-12) }\end{array}$ & & & & \\
\hline $\begin{array}{l}\text { Baley (1982) } \\
16 \text { Contemporary Violin Etudes (13-16) }\end{array}$ & & & & \\
\hline $\begin{array}{l}\text { Berio (1983) } \\
\text { Duetti per due violini }\end{array}$ & & & & \\
\hline $\begin{array}{l}\text { *Adler (1996) } \\
\text { Meadowmountetudes }\end{array}$ & & & & \\
\hline
\end{tabular}

Tab. 3: Obras de caráter musical e pedagógico mencionadas no texto e as categorias de técnicas principalmente abrangidas por elas. *Asteriscos marcam obras analisadas previamente por Buckles (2003) e não enfocadas diretamente no presente artigo. Fonte: Elaborado pelo autor (2020).

Pode ser observado, portanto, que as técnicas derivadas da linguagem rítmica e harmônica característica da música moderna (categoria 1) não apenas predominam na literatura em questão, como também formam a única categoria de técnicas estendidas explorada isoladamente. Isso pode ser o simples reflexo da evolução dos processos composicionais ao longo do século $X X$, em que a proliferação da utilização das demais categorias se deu quando idiomas rítmicos e harmônicos já haviam evoluído para muito além dos estilos vigentes até o final do século XIX. No entanto, considerando-se o alto grau de complexidade comum no repertório com técnicas estendidas (algo que em parte motivou o trabalho de Krewer [2019], por exemplo), cabe questionar se, para fins didáticos, não seria pertinente o desenvolvimento de obras que explorassem categorias 2, 3 ou 4 também isoladamente, como, por exemplo, peças predominantemente dentro da linguagem rítmica e harmônica clássico-romântica, porém com a predominância de efeitos de produção de som estendidos (no caso da categoria 2).

É verdade que as peças didáticas dentro da categoria 2 discutidas aqui cobrem uma considerável variedade de níveis, no entanto, as obras de menor complexidade exploram uma pequena variedade de técnicas (geralmente sul ponticello e sul tasto - como no caso dos duetos de Berio), ao passo que, quanto maior a diversidade de técnicas de produção de som, maior também a complexidade de outros aspectos que envolvem as 
demais categorias (como é visível nos estudos de Baley, por exemplo). A Tab. 4 coloca as obras de autores que contêm técnicas da categoria 2 de acordo com os respectivos níveis abrangidos.

\begin{tabular}{|l|l|l|l|}
\hline & Iniciante & Intermediário & Avançado \\
\hline Berio (1983) & & & \\
Duetti per due violini & & & \\
\hline Blank (1982) & & & \\
16 Contemporary Violin Etudes (1-4) & & & \\
\hline $\begin{array}{l}\text { Flynn (1982) } \\
16 \text { Contemporary Violin Etudes (9-12) }\end{array}$ & & & \\
\hline Baley (1982) & & & \\
16 Contemporary Violin Etudes (13-16) & & & \\
\hline${ }^{*}$ Cage (1981) & & & \\
Freeman Etudes & & & \\
\hline
\end{tabular}

Tab. 4: Autores de obras que abrangem a categoria 2 de acordo com nível de complexidade. *Asteriscos marcam obras analisadas previamente por Buckles (2003) e não enfocadas diretamente no presente artigo. Fonte: Elaborado pelo autor (2020).

\section{CONSIDERAÇÕES FINAIS}

O ensino de técnicas estendidas para violino é uma das ferramentas para a familiarização de alunos de instrumento com os idiomas musicais dos séculos XX e XXI e, consequentemente, para incentivar a aproximação com compositores em atividade na atualidade. Como foi discutido, já existe uma considerável quantidade de trabalhos com relevância para o estudo de técnicas estendidas violinísticas, apesar de não se encontrarem dentre as obras mais utilizadas na prática. Isso não quer dizer que não haja lacunas, já que muitas dessas obras, por exemplo, não dizem respeito a técnicas de produção de som. Para fins de uma investigação mais detalhada sobre o tema, foram propostas então categorias de técnicas estendidas, tendo sido colocado um enfoque na categoria de técnicas de produção de som específicas do violino. A pesquisa identificou como esta categoria de técnicas tem sido contemplada nas últimas quatro décadas dentro de uma amostragem de obras textuais (livros, teses e dissertações) e musicais.

As nove obras textuais dentro da amostragem selecionada abordam o tema de diversas formas e, mesmo sendo todas de alguma forma relevantes para o aprendizado e ensino das técnicas, apenas quatro delas (SARCH, 1982; VAN DER MERWE, 2005; BUDÓ, 2018; KREWER, 2019) têm caráter decididamente didático. O repertório contemplado na maioria das obras é primariamente por compositores europeus e estadunidenses, exceto no caso de três obras (LÔBO, 2016; RUFINO, 2017; BUDÓ, 2018) que buscam especificamente compositores fora deste eixo. Três obras (ARDITTI; PLATZ, 2013; RUFINO, 2017; BUDÓ, 2018) incluem algum tipo de recurso auditivo, visual ou audiovisual, e duas outras (STRANGE; STRANGE, 2001; TISCHHAUSER, 2003) trazem discografias do repertório analisado. Dentre as cinco obras musicais didáticas dentro da amostragem discutida, quatro(CAGE, 1981;BLANK, 1982;FLYNN, 1982;BALEY,1982)abrangemacategoria de técnicas de produção de som específicas do violino. Dessas quatro, há vários 
níveis abrangidos, sendo observado entretanto que as peças de menor complexidade incluem uma diversidade muito limitada de técnicas de produção de som (geralmente sul ponticello, sul tasto e col legno), ao passo que as obras com maior diversidade são pouco acessíveis a instrumentistas iniciantes e intermediários.

\section{Referências}

ARDITTI, Irvine; PLATZ, Robert HP. The techniques of violin playing. Kassel: Barenreiter, 2013. 117p.

BERIO, Luciano. Duetti per due violini. Milano: Universal Edition, 1983.

BERIO, Luciano. Duetti per due violini (author's note). Disponível em: http://www. lucianoberio.org/node/1371 ?237685848=1. Acesso em: 6 mar. 2020.

BUCKLES, Michael Kim. A structured content analysis of five contemporary etude books for the violin. 2003. 436 p. Tese (Doutorado)-Louisiana State University and Agricultural \& Mechanical College, 2003.

BUDÓ, Lourenço De Nardin. Analysis of uncompiled extended violin techniques with didactic musical and audiovisual examples. 2018. $93 \mathrm{f}$. Tese (Doutorado) - University of Georgia, Athens, 2018.

COPETTI, Rafaela; TOKESHI, Eliane. Técnica expandida para violino: classificação e avaliação de seu emprego na música brasileira. In: CONGRESSO DA ASSOCIAÇÃO NACIONAL DE PESQUISA E PÓS-GRADUAÇÃO EM MÚSICA, 15., 2005. Anais [...]. Rio de Janeiro: Universidade Federal do Rio de Janeiro, 2005. p. 318-323.

FERRAZ, Sílvio; PADOVANI, José Henrique. Proto-história, evolução e situação atual das técnicas estendidas na criação musical e na performance. Música Hodie, v. 11, n. 2, p. 11-35, 2011.

GALAMIAN, Ivan; NEUMANN, Frederick. Contemporary violin technique. New York: Galaxy Music Corporation, 1966.

KREWER, Mariana. Extended techniques for intermediate violin students. 2018.119f. Tese (Doutorado) - Louisiana State University and Agricultural \& Mechanical College, 2018.

KUBALA, Ricardo Lobo; TOKESHI, Eliane. Refletindo sobre técnica estendida. In: PRESGRAVE, Fabio Soren; MENDES, Jena JoubertFreitas; NODA, Luciana (org.). Ensaios sobre a música dos séculos XX e XXI: composição, performance e projetos colaborativos. Vol. 1. Natal: Ed. UFRN, 2016. p. 185-195. 
LÔBO, Rodrigo de Almeida Eloy. Compositor e intérprete: reflexões sobre colaboração e processo criativo em Caminho Anacoluto II - quasi-Vanitas de Marcílio Onofre. 2016. 83 f. Dissertação (Mestrado) - Universidade Federal da Paraíba, João Pessoa, 2016.

RUFINO, Vladimir Machado. Styles and extended techniques in 6 works for violin from Paraíba since 1952. 2017. 38 f. Dissertação (Mestrado) - University of Alberta, Edmonton, 2017.

SARCH, Kenneth Lee. The twentieth century violin: a treatise on contemporary violin technique. 1982. 305 p. Tese (Doutorado) - Boston University, Boston, 1982.

SPOSITO, Tauan Gonzales. A aplicação de técnicas estendidas no ensino de violino e viola. In: ENCONTRO REGIONAL SUL DA ASSOCAIÇÃO BRASILEIRA DE EDUCAÇÃO MUSICAL, 7., 2016, Curitiba. Anais [...]. Curitiba: Abem, 2016. Disponível em http:// abemeducacaomusical.com.br/conferencias/index.php/xviiregsul/regs2016/paper/ view/1962. Acesso em: 28 fev. 2020.

STRANGE, Allen; STRANGE, Patricia. The contemporary violin: extended performance techniques. Berkeley: University of California Press, 2001. 337p.

TISCHHAUSER, Katherine Jetter. A survey of the use of extended techniques and their notations in twentieth century string quartets written since 1933 by american composers with a selected annotated bibliography and discography. 2002. $161 \mathrm{f}$. Tese (Doutorado) - Florida State University, Tallahassee, 2002.

TOKESHI, Eliane. Técnica expandida para violino e as variações opcionais de GuerraPeixe: reflexão sobre parâmetros para interpretação musical. Música Hodie, Goiânia, v. 3 , n. $1 / 2$, p. 52-58, 2004.

VAN DER MERWE, Brenda. New frontiers in the art of violin performance: the contemporary study and pedagogy of extended performance techniques for the violin. 2005. 195 f. Tese (Doutorado) - Boston University, Boston, 2005. 